\title{
3,5-Diiodo-L-Thyronine Modifies the Lipid Droplet Composition in a Model of Hepatosteatosis
}

\author{
Elena Grassellia, Adriana Voci ${ }^{a}$ Laura Canesi ${ }^{a, c}$ Annalisa Salis ${ }^{b, e} \quad$ Gianluca Damonte ${ }^{b, e}$ \\ Andrea D. Compalatia Fernando Goglia ${ }^{d}$ Gabriella Gallo ${ }^{a}$ Laura Vergania,c \\ aDipartimento di Scienze della Terra, dell'Ambiente e della Vita, Università degli Studi di Genova, \\ Genova, bDipartimento di Medicina Sperimentale, Università degli Studi di Genova, Genova, Istituto \\ Nazionale Biostrutture e Biosistemi (INBB), Roma, 'Dipartimento di Scienze Biologiche ed Ambientali, \\ Università degli Studi del Sannio, Benevento, eCentro di Eccellenza per lo studio dei meccanismi \\ molecolari di comunicazione tra cellule: dalla ricerca di base alla clinica, Università di Genova, Genova, \\ Italy
}

\section{Key Words}

3,5-Diiodo-L-thyronine $\left(\mathrm{T}_{2}\right) \cdot$ Steatotic hepatocytes - Lipid droplets $\cdot$ Saturated/unsaturated fatty acids $\cdot$ PAT proteins

\begin{abstract}
Background/Aims: Fatty acids are the main energy stores and the major membrane components of the cells. In the hepatocyte, fatty acids are esterified to triacylglycerols (TAGs) and stored in lipid droplets (LDs). The lipid lowering action of 3,5-diiodo-L-thyronine $\left(T_{2}\right)$ on an in vitro model of hepatosteatosis was investigated in terms of fatty acid and protein content of LDs, lipid oxidation and secretion. Methods: FaO cells were exposed to oleate/ palmitate, then treated with $T_{2}$. Results: $T_{2}$ reduced number and size of LDs, and modified their acyl composition by decreasing the content of saturated (SFA) vs monounsaturated (MUFA) fatty acids thus reversing the SFA/MUFA ratio. The expression of the LD-associated proteins adipose differentiation-related protein (ADRP), oxidative tissue-enriched PAT protein (OXPAT), and adipose triglyceride lipase (ATGL) was increased in 'steatotic' cells and further up-regulated by $T_{2}$. Moreover, $T_{2}$ stimulated the mitochondrial oxidation by up-regulating carnitine-palmitoyl-transferase (CPT1), uncoupling protein 2 (UCP2) and very long-chain acylcoenzyme A dehydrogenase (VLCAD). Conclusions: $T_{2}$ leads to mobilization of TAGs from LDs and stimulates mitochondrial oxidative metabolism of fatty acids, in particular of SFAs, and thus enriches of MUFAs the LDs. This action may protect the hepatocyte from excess of SFAs that are more toxic than MUFAs.
\end{abstract}


Grasselli et al.: $\mathrm{T}_{2}$ and Lipid Droplet Composition

\section{Introduction}

Fatty acids are the main energy stores and the major membrane components in the cell, but their excess is toxic and induces several dysfunctions including apoptosis [1]. Increased circulating levels of non-esterified fatty acids (NEFAs) result in a pathological condition called non-alcoholic fatty liver disease (NAFLD) or hepatic steatosis.

NEFAs taken up by the hepatocyte are esterified to triacylglycerols (TAGs) and stored inside lipid droplets (LDs) that represent a defense mechanism against NEFA toxicity [2]. LDs are composed of a neutral lipid core, mainly TAG and cholesterol esters, surrounded by amphipathic proteins of the PAT family (acronym referring to the first members identified) [3]. In mammalian liver, the main PAT members include adipose differentiation-related protein (ADRP), and oxidative tissue-enriched PAT protein (OXPAT). PAT proteins regulate the interface between LDs and cytosol. The lipid core composition of LDs depends on the cell type and adapts to the pathophysiological context [4]. The lipids stored in LDs can be catabolized through a functional network localized at the LD surface. The adipose triglyceride lipase (ATGL) catalyzes the first reaction hydrolyzing TAGs to diacylglycerol and NEFAs [5]. In mice, ATGL deficiency is associated with reduced lipolysis and increased fat deposition [6]; in humans, ATGL mutations are associated with TAG accumulation [6].

Mitochondria are the main cellular district for oxidation of fatty acids. Very longchain acyl-CoA dehydrogenase (VLCAD) catalyzes the first reaction in the mitochondrial $\beta$-oxidation of long-chain fatty acids [7]. Moreover, mitochondrial oxidation is regulated by carnitine-palmitoyl-transferase 1 (CPT1) that acts in the transport of long and very long fatty acids into the mitochondria, and by uncoupling protein 2 (UCP2) that reduces membrane potential. CPT1 is the rate-limiting step for a major part of $\beta$-oxidation [8]; UCP2 prevents the development of hepatosteatosis and steatohepatitis [9] and is associated with the recovery from liver injury [10]. Fatty acids are also degraded in peroxisomes where acyl CoA oxidase (AOX) is the rate-limiting enzyme of this metabolic pathway.

The saturated palmitic acid (PA, 16:0), and the monounsaturated oleic acid (OA, 9-cis 18:1), are the most abundant fatty acids present in both the diet and the serum. In rodent cells, high concentrations of PA induce apoptosis, whereas OA prevents cell death and promotes formation of the very low density lipoproteins (VLDL) responsible for the transport of lipids in the blood [11]. The major protein component of VLDL is apolipoprotein B (ApoB) that exists in two forms in humans and rodents, ApoB100 and ApoB48 [12], expressed also in isolated rat hepatocytes [13].

The liver is a central organ for lipid metabolism [14], and the target for the thyroid hormones (THs) thyroxine $\left(\mathrm{T}_{4}\right)$ and 3,3,5-L-triiodothyronine $\left(\mathrm{T}_{3}\right)$ that modulate energy balance and lipid metabolism. Other iodothyronines display some thyromimetic activities, in particular, 3,5-diiodo-L-thyronine $\left(\mathrm{T}_{2}\right)$, derived from peripheral 5'-deiodination of $\mathrm{T}_{3}$ [15], mimics several effects of $\mathrm{T}_{3}$ on energy metabolism without inducing thyrotoxic effects in both rats [16] and humans [17]. $\mathrm{T}_{2}$ was able to both prevent $[16,18]$ and reduce [19] the development of liver steatosis when administered to rats receiving a high-fat diet (HFD). Recent experiments of our group performed using primary rat hepatocytes overloaded with lipids demonstrated that $\mathrm{T}_{2}$ was able to reduce the excess fat by acting directly on the hepatic cell [20]. Moreover, using the hepatoma FaO cells, defective for functional thyroid hormone receptors (TRs), we could demonstrate that $\mathrm{T}_{2}$ was able to decrease the excess lipid content through TR-independent mechanisms of action [21].

In this work, the lipid lowering effect and mechanisms of action of $\mathrm{T}_{2}$ on lipid homeostasis were investigated in 'steatotic' FaO cells, with particular regards on its effects on both fatty acid and protein components of LDs, as well as on lipid secretion and oxidation pathways. 


\section{Materials and Methods}

\section{Chemicals}

All chemicals, unless otherwise indicated, were of analytical grade and were obtained from SigmaAldrich (Milan, Italy).

\section{Cell Culture}

Rat hepatoma cell line (FaO), supplied by European Collection of Cell Cultures (ECACC, Salisbury, UK), is a well-differentiated cell line retaining many of the specific markers and biochemical functions of hepatocytes including secretion of lipoproteins [22,23]. Cells were grown at $37^{\circ} \mathrm{C}$ in Coon's modified Ham's F12 supplemented with $10 \%$ foetal bovine serum-FBS (Euroclone, Milan, Italy). For experiments, FaO cells were seeded on Petri dishes and used at 70-80\% confluence. Before treatments cells were incubated in starvation medium supplemented with $0.25 \%$ bovine serum albumin (BSA) without FBS. Cells were treated with a mixture of oleate/palmitate (2:1 molar ratio, total concentration $0.75 \mathrm{mM}$, NEFA) for $3 \mathrm{~h}$ [24]. This NEFA concentration is similar to the plasmatic NEFA levels $(0.2-0.5 \mathrm{mM})$ measured in patients with metabolic syndrome [25]. Then, medium was replaced with fresh medium containing high purity (>98\%) $\mathrm{T}_{2}$, or $\mathrm{T}_{3}$, for comparison, at different concentrations (nominal concentrations ranging from $10^{-6} \mathrm{M}$ to $10^{-5} \mathrm{M}$ ) for $24 \mathrm{~h}$ [21]. Control cells (C) were incubated in the medium without addition of NEFAs and iodothyronines. At the end of treatment, cells were collected and stored at $-80^{\circ} \mathrm{C}$. Cell viability, as assessed by Trypan blue exclusion test was not affected by exposure to NEFAs nor iodothyronines.

\section{Lipid quantification}

TAG content was quantified using the 'Triglycerides liquid' kit (Sentinel, Milan, Italy) that allows to quantify glycerol as a measure of insoluble TAGs extracted with chloroform-methanol (v/v) mixture [24]. A Varian Cary 50 spectrophotometer (Agilent, Milan, Italy) was used for spectrophotometric analysis. Values were normalized for the protein content determined by the bicinchoninic acid (BCA) assay using BSA as a standard [26]. Data are expressed as percent TAG content relative to controls.

\section{Detection of LDs by Fluorescent Microscopy}

Neutral lipids stored in LDs were visualized by fluorescence microscopy using BODIPY 493/503 dye (Molecular Probes, Life technologies, Monza, Italy) [27]. Cells grown on coverslips were rinsed with phosphate-buffered saline (PBS) pH 7.4 and fixed with 4\% paraformaldehyde in PBS for 20 min at room temperature. Then, slides were incubated with $1 \mu \mathrm{g} / \mathrm{ml}$ BODIPY in PBS for $30 \mathrm{~min}$, washed and mounted with 4',6-diamidino-2-phenylindole (DAPI) for examination by Nikon Eclipse E80i light microscope (Nikon, Tokyo Japan) equipped with the standard epifluorescence filter set up for DAPI and FITC. For determination of LD diameter images were captured under oil with a 100x plan apochromat objective. Analyses were performed on two independent experiments measuring at least 40 cells for each treatment using imageJ software (http://rsb.info.nih.gov/ij/ site).

\section{LD isolation and composition}

Lipid droplets were isolated from 'steatotic' FaO cells incubated in the absence or in the presence of $\mathrm{T}_{2} 10^{-5} \mathrm{M}$ following a standard protocol with minor modifications [28]. FaO cells where scraped from the dishes in PBS buffer containing $5 \mathrm{mM} \mathrm{MgCl}_{2}$ and a cocktail of protease inhibitors. Cell suspension (about $40 \times 10^{6}$ cells/sample) was homogenized with a glass dounce homogenizer on ice, and centrifuged at $800 \mathrm{xg}$ for $10 \mathrm{~min}$ at $4^{\circ} \mathrm{C}$. The supernatant was centrifuged at 5,000 xg for $20 \mathrm{~min}$. Then the supernatant was further centrifuged at 43,000 rpm in SW55 rotor $(230,000 \mathrm{xg})$ for $2 \mathrm{~h}$ at $4^{\circ} \mathrm{C}$. The LD fraction forming a distinct white band on the surface of the preparation was collected. Lipids were then extracted from isolated LDs using the method of Folch et al. [29]. Briefly, the lipid phase was saponified with methanolic $\mathrm{KOH}$ (3M) for 60 min at $80^{\circ} \mathrm{C}$. After cooling, the non saponifiable lipids were extracted by two washings with diethylether, and the aqueous phase was acidified with $\mathrm{HCl} 6 \mathrm{M}$ and extracted with n-hexane. The hexane phases containing NEFAs were collected, the solvent evaporated, and the residue derivatized by acid-catalyzed esterification [30]. Briefly, NEFAs were methylated in $14 \% \mathrm{BF}_{3} / \mathrm{CH}_{3} \mathrm{OH}$ for $5 \mathrm{~min}$ at $100^{\circ} \mathrm{C}$, and extracted with a mixture of $n$-hexane: water (2:1). After centrifugation (500xg) the hexane phase was collected and the aqueous phase was further extracted with n-hexane. The two extracted fractions were pooled and dried under 
Grasselli et al.: $\mathrm{T}_{2}$ and Lipid Droplet Composition

nitrogen. Samples resuspended in hexane were injected in a HP5890 series II gas chromatograph coupled to a HP5970 mass spectrometer equipped with an electron impact ionization source (Agilent). Separation was performed on a DB5MS capillary column (Phenomenex, $0.25 \mathrm{~mm} \times 30 \mathrm{~m}$ ); the helium gas flow was $1 \mathrm{ml} / \mathrm{min}$. The oven temperature gradient was as follows: initial temperature of $100^{\circ} \mathrm{C}$, isothermal at $100^{\circ} \mathrm{C}$ for $3 \mathrm{~min}$, 100 to $300^{\circ} \mathrm{C}$ (rate, $15^{\circ} \mathrm{C} / \mathrm{min}$ ) and isothermal at $300^{\circ} \mathrm{C}$ for $5 \mathrm{~min}$. The $\mathrm{MS}$ analysis was performed in fullscan mode. FAME (fatty acid methyl ester) quantification was performed using a calibration curve obtained injecting different FAME standards referring to selected ions. The most abundant and specific ions were used for the quantification of FAMEs: $\mathrm{m} / \mathrm{z} 74$ was used for saturated FAMEs and m/z 55 for monosaturated FAMEs. The regression curves were linear in the range of the FAME concentrations used for the analysis.

\section{RNA extraction and real-time qPCR}

Total RNA was isolated using the Trizol reagent according to the manufacturers' instructions [31]. First strand cDNA was synthesized from total RNA by using M-MuLV Reverse Transcriptase (Fermentas, Dasit, Milan, Italy) [24]. Quantitative real time PCR (qPCR) was performed in quadruplicate using $1 \mathrm{x} \mathrm{IQ}^{\mathrm{TM}}$ Sybr Green PCR Super Mix and Chromo4 ${ }^{\mathrm{TM}}$ System PCR apparatus (Biorad, Milan, Italy). The thermal protocol and the primer pairs were described elsewhere [18, 20, 24, 32-34]. The quantification cycle (Cq) represents the cycle number at which the amount of amplified target reaches the fixed threshold. The relative quantity of target mRNA was calculated by using the comparative $\mathrm{Cq}$ method and was normalized for the expression of glyceraldehyde 3-phosphate dehydrogenase (GAPDH). The normalized expression was expressed as relative quantity of mRNA (fold induction) with respect to controls [35].

\section{Western Blot}

For ApoB immunodetection cells were lysed in buffer containing $150 \mathrm{mM} \mathrm{NaCl}, 50 \mathrm{mM}$ Tris $\mathrm{HCl}, 0.33 \%$ SDS, $8 \mathrm{mM}$ PMSF, $8 \mathrm{mM}$ DTT, $8 \mathrm{mM} \mathrm{Na}_{3} \mathrm{VO}_{4}$, cocktail of protease inhibitors (pH 7.4), whereas for both CPT1 and UCP2 $1 \%$ Triton and 1\% Natrium deoxycholate were added. Thirty-five to fifty micrograms of protein extract of each sample were electrophoresed at $70 \mathrm{~mA}$ on 12\%SDS-polyacrylamide gel (SDS-PAGE) [36]. The gel was electroblotted onto a nitrocellulose membrane using CAPS buffer ( $0.1 \mathrm{M}$ CAPS, $10 \%$ methanol, $0.01 \%$ SDS; pH 11) for ApoB, and Towbin buffer (25 mM Tris HCl, $192 \mathrm{mM}$ glycine, 20\% methanol; pH8.3) for both UCP2 and CPT1 [37]. Then, membrane was blocked for $1 \mathrm{~h}$ in $5 \%$ fat-free milk/PBS pH 7.4 solution. As primary antibodies we used rabbit anti-human ApoB IgG (SC-25542), goat anti-human UCP2 IgG (SC6525), and rabbit anti-human CPT1 IgG (SC-20669) supplied by Santa Cruz Biotechnology (DBA, Milan, Italy). Membranes were incubated overnight at $4^{\circ} \mathrm{C}$ with primary antibody PBS, then washed twice in PBST buffer (0.1 M phosphate buffer, $0.0027 \mathrm{M} \mathrm{KCl}, 0.137 \mathrm{M} \mathrm{NaCl}$ and $0.1 \%$ Tween 20, pH 7.4) and once in PBS ( $0.1 \mathrm{M}$ phosphate buffer, $0.0027 \mathrm{M} \mathrm{KCl}$ and $0.137 \mathrm{M} \mathrm{NaCl} \mathrm{pH} \mathrm{7.4).} \mathrm{Then,} \mathrm{membranes} \mathrm{were} \mathrm{incubated} \mathrm{with}$ horseradish peroxidase (HRP)-conjugated goat anti-rabbit IgG (Sigma-Aldrich) or rabbit anti-goat IgG (Biorad) as a secondary antibody in PBST for $1 \mathrm{~h}$ at room temperature. Protein molecular weight markers were from Biorad (Plus Protein ${ }^{\mathrm{TM}}$ Dual Xtra Standards). As loading controls, membrane was stripped and reprobed with rabbit anti-actin antibody (Sigma-Aldrich) diluted 1:500 in 5\% milk/PBS. Immune complexes were visualized using an enhanced chemiluminescence western blotting analysis system (Bio-Rad ChemiDoc XRS System). Western blot films were digitized and band optical densities were quantified against the actin band using a computerized imaging system and expressed as Relative Optical Density (ROD, arbitrary units). ROD of each band was expressed as percentage respect to control.

\section{Determination of AOX activity}

AOX activity was determined spectrophotometrically in the 12,000xg supernatant fraction of cell lysates by following oxidation of leuco-dichlorofluorescein (DCFA) catalyzed by exogenous peroxidase at $25^{\circ} \mathrm{C}$ [38]. AOX specific activity was expressed as nanomoles of $\mathrm{H}_{2} \mathrm{O}_{2}$ decomposed per min/mg of sample protein.

\section{Statistics}

Data on qPCR are means \pm S.D. of at least four independent experiments and each measurement was performed in quadruplicate. Data on Western blot are means \pm S.D. of five independent experiments. Data on FAME content of $\mathrm{LD}$ are means \pm S.D. of three independent experiments. The significance of the difference between groups was ANOVA plus Tukey's post-test (GraphPad Software Inc., San Diego, CA92130USA). 


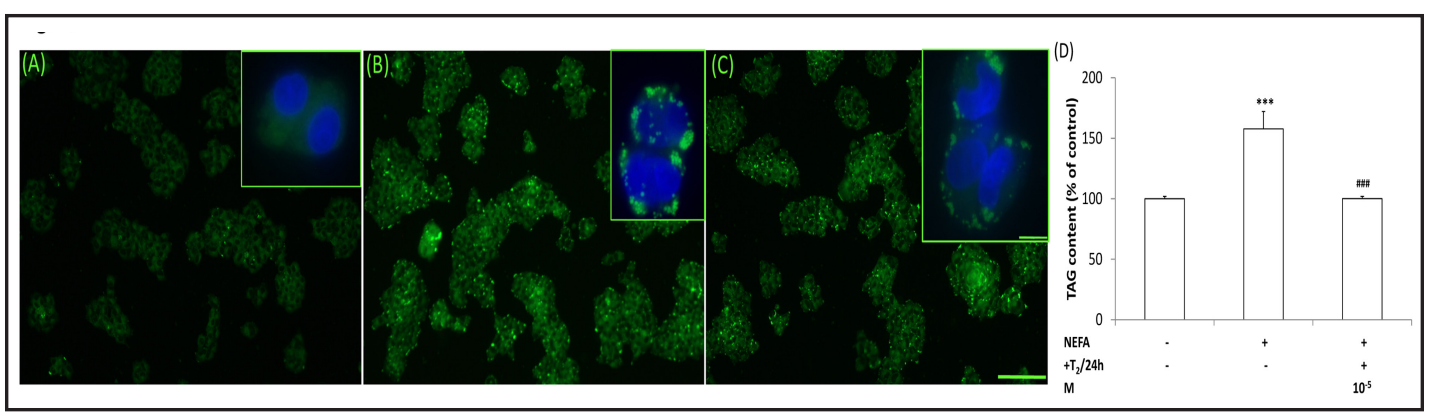

Fig. 1. Effects of $T_{2}$ on lipid accumulation in 'steatotic' hepatoma cells. Lipid content was visualized by fluorescence microscopy in control (A), and in 'steatotic' FaO cells incubated for $24 \mathrm{~h}$ in the absence (B) or in the presence (C) of $\mathrm{T}_{2}\left(10^{-5} \mathrm{M}\right)$. Lipids were stained by BODIPY 493/503 and images acquired at both 40x (A, B, C) and 100x magnification (inset) respectively (Bar:100 and $10 \mu \mathrm{m}$ respectively). On the 100x images the average diameter of LDs was measured using imageJ software. The intracellular TAG content (D) was quantified by spectrophotometric assay in control, and in 'steatotic' cells incubated in the absence or in the presence of $\mathrm{T}_{2}\left(10^{-5} \mathrm{M}\right)$; results are expressed as mean \pm S.D. from five independent experiments. Significant differences are denoted by symbols on bars (C versus NEFA *** $\mathrm{p} \leq 0.001$; NEFA versus THs, \#\#\# $\mathrm{p} \leq 0.001$ ).

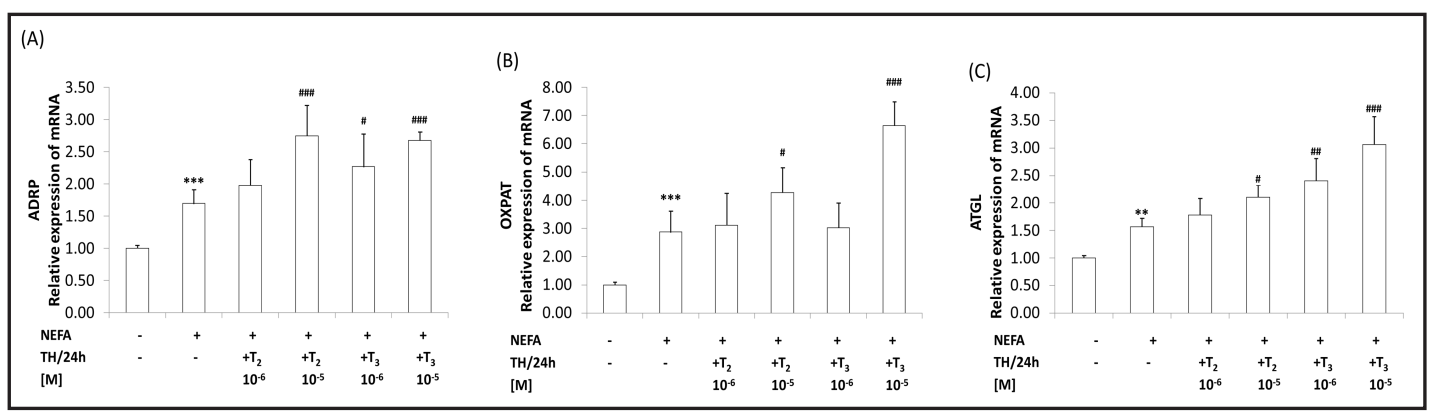

Fig. 2. $\mathrm{T}_{2}$ up-regulated mRNA expression of LD-associated proteins. Relative mRNA expression of ADRP (A), OXPAT (B), and ATGL (C) was evaluated by qPCR in control (C) and 'steatotic' cells incubated in the absence (NEFA) or in the presence of $\mathrm{T}_{2}$ or $\mathrm{T}_{3}\left(10^{-6}\right.$ and $\left.10^{-5} \mathrm{M}\right)$. GAPDH was used as the internal control for quantifying gene expression. Data, expressed with respect to controls, are the mean \pm S.D. of at least four experiments in triplicate. Significant differences are denoted by symbols on bars (C versus NEFA *** $\mathrm{p} \leq 0.001 ;{ }^{* *} \mathrm{p} \leq 0.01$; NEFA versus THs \#\#\# $\mathrm{p} \leq 0.001$; \#\# $\mathrm{p} \leq 0.01 ; \# \mathrm{p} \leq 0.05$ ).

\section{Results}

\section{Effects of $T_{2}$ on $L D S$}

Exposure of $\mathrm{FaO}$ cells to exogenous NEFAs (steatotic cells) for $3 \mathrm{~h}$ led to lipid accumulation resulting in an increase in the number and size of LDs that were visualized by BODIPY staining (Fig. 1). In control cells, few small LDs (about $0.9 \pm 0.3 \mu \mathrm{m}$ in size) were dispersed in the cytosol (Fig. 1A). In 'steatotic' cells, together with small LDs, also numerous larger droplets (about $1.9 \pm 0.2 \mu \mathrm{m}$ ) could be appreciated (Fig. 1B, inset) this resulting in an average increase in LD diameter of about $+80 \%(\mathrm{p} \leq 0.001)$ with respect to control cells. When 'steatotic' cells were treated for $24 \mathrm{~h}$ with $\mathrm{T}_{2}\left(10^{-5} \mathrm{M}\right)$ we observed a decrease in the number and size of LDs, whose average diameter was reduced to a value more similar to that of control cells (about $1.25 \pm 0.2 \mu \mathrm{m}$ ) (Fig. 1C). The $\mathrm{T}_{2}$-induced decrease in LD size was associated with a reduction of the intracellular TAG content (from about $160 \%$ of 'steatotic' cells to $100 \%$ of $\mathrm{T}_{2}$-treated cells calculated with respect to control) (Fig. 1D).

The mRNA level of the main PAT proteins was analyzed by qPCR. Excess in lipid accumulation resulted in a significant up-regulation of both ADRP and OXPAT mRNA expression with respect to controls (about 1.7 fold and 2.9 fold, respectively; $p \leq 0.001$ ) (Fig. 2 ). The transcription of both ADRP and OXPAT was further increased when 'steatotic' cells 
Fig. 3. $\mathrm{T}_{2}$ modified the fatty acid composition of LDs. The fatty acid composition of esterified TAGs extracted from purified LDs was determined by gas chromatography in 'steatotic' cells incubated for $24 \mathrm{~h}$ in the absence (NEFA) or in the presence of $\mathrm{T}_{2}\left(10^{-5} \mathrm{M}\right)$. FAME quantification of lauric acid (LA, 12:0), myristic acid (MA, 14:0), pentadecanoic acid (PEA, 15:0), palmitic acid (PA, 16:0), palmitoleic acid (PLA, 16:1), stearic acid (SA, 18:0), and oleic acid (OA, 18:1). Data (percentage) are expressed as the mean \pm S.D. of three experiments. Ratios between the SFA

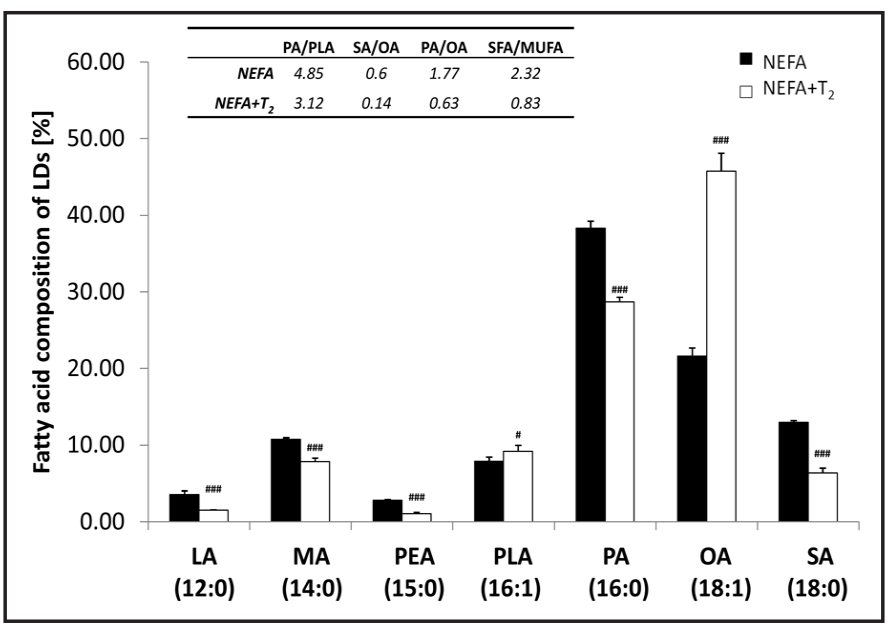
and the corresponding MUFA as well as the totality of SFA/MUFA ratio are reported in the inset. Significant differences are denoted by symbols on bars (NEFA versus NEFA $+\mathrm{T}_{2} 10^{-5} \mathrm{M}$, \#\#\# $\mathrm{p} \leq 0.001 ; \# \mathrm{p} \leq 0.05$ ).

were treated with $\mathrm{T}_{2}$ (about $+62 \%$ for ADRP, and $+49 \%$ for OXPAT, at the highest dose of $\mathrm{T}_{2}$ with respect to 'steatotic' cells, $\mathrm{p} \leq 0.001$ and $\mathrm{p} \leq 0.05$, respectively) (Fig. 2A-B). A significant increase was also induced by $\mathrm{T}_{3}$ used as comparison (about $+58 \%$ for ADRP, and $+131 \%$ for OXPAT at the highest dose of $\mathrm{T}_{3}$ with respect to 'steatotic' cells; $\mathrm{p} \leq 0.001$ ) (Fig. 2A-B). On the other hand, neither $\mathrm{T}_{2}$ nor $\mathrm{T}_{3}$ affected OXPAT and ADRP mRNA expression in control cells (data not shown).

Lipid mobilization from LDs is mainly regulated by ATGL [39]. A slight but significant increase in ATGL transcript was observed in 'steatotic' FaO cells with respect to control (about 1.6 fold; $\mathrm{p} \leq 0.01$ ) (Fig. 2C). ATGL mRNA expression was further up-regulated when 'steatotic' cells were treated with the highest dose of $\mathrm{T}_{2}$ (about $+34 \%$ with respect to 'steatotic' cells, $\mathrm{p} \leq 0.05$ ). Similar effect was observed with $\mathrm{T}_{3}$ (about $+53 \%$ for $10^{-6} \mathrm{M}$ dose, and $+95 \%$ for $10^{-5}$ $\mathrm{M}$ dose with respect to 'steatotic' cells, $\mathrm{p} \leq 0.01$ and $\mathrm{p} \leq 0.001$, respectively). Neither $\mathrm{T}_{2}$ nor $\mathrm{T}_{3}$ affected mRNA expression of ATGL in control cells (data not shown).

\section{Effects of $T_{2}$ on the fatty acid composition of $L D S$}

When $\mathrm{FaO}$ cells were incubated for $3 \mathrm{~h}$ in the presence of the oleate/palmitate mixture, the gas chromatography analysis of the purified LDs revealed that the acyl composition of their TAGs (Fig. 3) was consistent with the saturated (SFA) and monounsaturated (MUFA) fatty acids typically found in mammalian cells, including lauric acid (LA, 12:0), myristic acid (MA, 14:0), pentadecanoic acid (PEA, 15:0), palmitic acid (PA, 16:0), palmitoleic acid (PLA, 16:1), stearic acid (SA, 18:0), and oleic acid (OA, 18:1). Treatment of 'steatotic' cells with $\mathrm{T}_{2}$ decreased the total content of fatty acids incorporated into TAGs of about $-50 \%$ (from $16.8 \pm 3.14 \mathrm{nmol} / \mathrm{mg}$ proteins to $9.7 \pm 2.02 \mathrm{nmol} / \mathrm{mg}$ proteins, respectively; $\mathrm{p} \leq 0.05$ ).

As summarized in Figure 3, LDs from 'steatotic' cells (NEFA) showed a prevalence of PA (about 38.3\%), followed by OA (about 21.6\%), SA (about 13\%), MA (about 10.8\%), PLA (about 7.9\%), LA (about 3.6\%), and PEA (about 2.8\%). Treatment with $\mathrm{T}_{2}$ modified the fatty acid profile of the LDs by reversing the PA/OA ratio (Fig. 3 inset). In fact, OA became the prevalent fatty acid (about 45.8\%) in LDs, while the PA content decreased to about $28.7 \%$. A decrease in the content of SA (to about 6.4\%), MA (to about 7.9\%), LA (to about 1.5\%), PLA (to about $9.2 \%$ ), and PEA (to about $1.1 \%$ ) was also observed.

\section{Effects of $\mathrm{T}_{2}$ on lipid secretion}

Total TAGs were quantified in the culture medium as an indication of lipid secretion (Fig. 4A). After exposure to NEFAs, the TAG content in the medium was increased of $+30 \%$ 


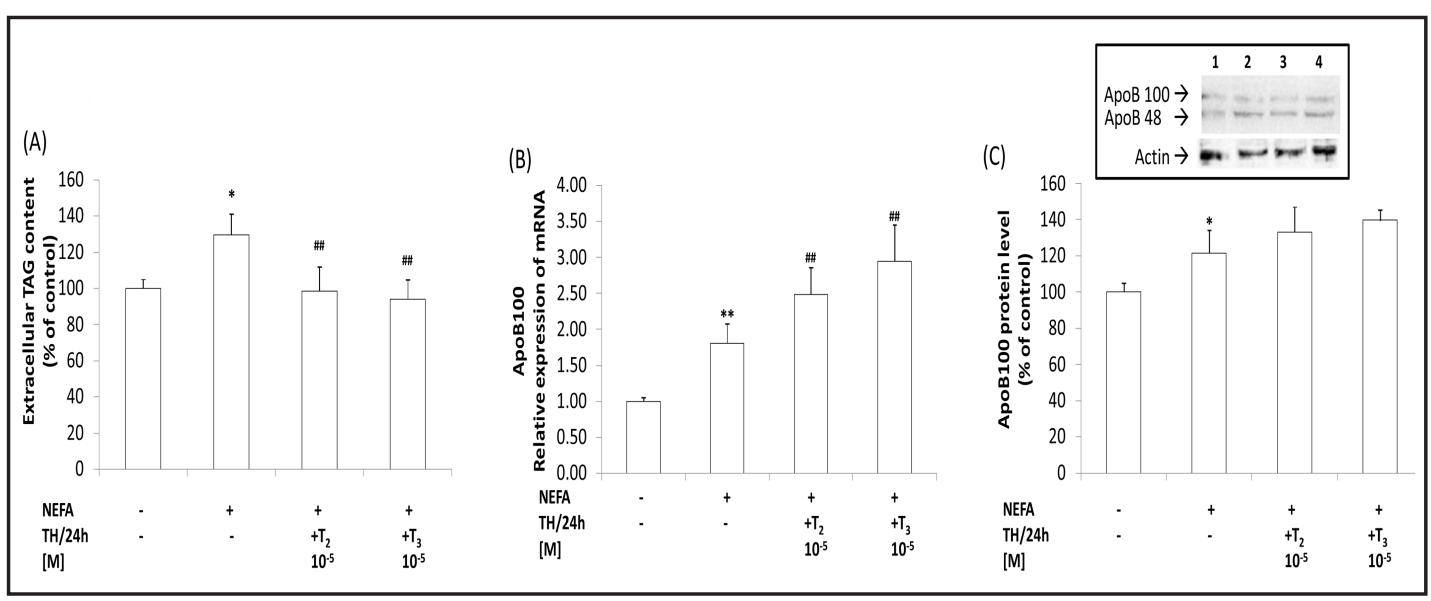

Fig. 4. $T_{2}$ reduced TAG secretion. (A) The extracellular TAG content was quantified in the culture medium in control (C) and 'steatotic' cells incubated in the absence (NEFA) or in the presence of $\mathrm{T}_{2}$ or $\mathrm{T}_{3}$ $\left(10^{-5} \mathrm{M}\right)$. Data, expressed as percent values with respect to controls, are the mean \pm S.D. of at four experiments in duplicate. Significant differences are denoted by symbols on bars (C versus NEFA * $p \leq 0.05$; NEFA versus THs \#\#\# p $\leq 0.001$, \#\# p $\leq 0.01$ ).The mRNA (B) and protein (C) levels of ApoB 100 were measured by qPCR and western blotting, respectively, in control (C) and 'steatotic' cells incubated in the absence (NEFA) or in the presence of $\mathrm{T}_{2}$ or $\mathrm{T}_{3}\left(10^{-5} \mathrm{M}\right)$. GAPDH was used as the internal control in qPCR; actin was the protein loading control in SDS-PAGE (lane1: control, lane2: NEFA, lane3: NEFA+ $\mathrm{T}_{2} 10^{-5} \mathrm{M}$, lane4: $\mathrm{NEFA}+\mathrm{T}_{3} 10^{-5} \mathrm{M}$ ). Arrows denote the position of both ApoB100 and ApoB48. Significant differences are denoted by symbols on bars ( $C$ versus NEFA* $\mathrm{p} \leq 0.05,{ }^{* *} \mathrm{p} \leq 0.01$; NEFA versus THs \#\# $\mathrm{p} \leq 0.01$ ).

$(\mathrm{p} \leq 0.05)$ with respect to controls. The incubation of 'steatotic' cells with $\mathrm{T}_{2}\left(10^{-5} \mathrm{M}\right)$ reduced the extracellular TAG content of about $-24 \%(\mathrm{p} \leq 0.01)$ with respect to untreated 'steatotic' cells. A similar decrease in extracellular TAGs was observed upon treatment with the same dose of $\mathrm{T}_{3}$ for comparison ( $-27 \%$ with respect to 'steatotic' cells; $\left.\mathrm{p} \leq 0.01\right)$.

Expression of $A$ poB, the main component of VLDL, was assessed in the different experimental conditions. ApoB exists in two forms, ApoB100 (M.W. 500 kDa) and ApoB48 (M.W. $250 \mathrm{kDa}$ ). Our primers are specific for ApoB100, whereas antibody used for western blot is directed versus a region common between ApoB100 and ApoB48. Excess lipid accumulation in $\mathrm{FaO}$ cells induced an increase in both mRNA and protein level of ApoB100 with respect to controls (about 1.8 fold, $\mathrm{p} \leq 0.01$ for $\mathrm{mRNA}$; about $+22 \%$, $\mathrm{p} \leq 0.05$ for protein) (Fig. 4B-C). Although ApoB100 mRNA level was further up-regulated by both $\mathrm{T}_{2}$ and $\mathrm{T}_{3}$ (about $+40 \%$, $\mathrm{p} \leq 0.01$ for $\mathrm{T}_{2}$, and about $+60 \%$, $\mathrm{p} \leq 0.01$ for $\mathrm{T}_{3}$ ), no significant increase in the protein level was observed. Neither $\mathrm{T}_{2}$ nor $\mathrm{T}_{3}$ affected $\mathrm{mRNA}$ and protein expression of ApoB in control cells (data not shown).

\section{Effects of $\mathrm{T}_{2}$ on fatty acid oxidation}

In peroxisomes, AOX specific activity was stimulated in 'steatotic' cells with respect to control (about $+40 \%$; $\mathrm{p} \leq 0.05$ ). Neither $\mathrm{T}_{2}$ nor $\mathrm{T}_{3}$ affected $\mathrm{AOX}$ activity when administered to 'steatotic' (Fig. 5A) or control cells (data not shown).

In mitochondria, expression of VLCAD (Fig. 5B) was up-regulated in 'steatotic' cells with respect to control (about 1.77 fold; $\mathrm{p} \leq 0.001$ ), and was further stimulated when 'steatotic' cells were treated with the highest dose of $\mathrm{T}_{2}$ (about $+35 \%$ with respect to 'steatotic' cells; $\mathrm{p} \leq 0.05$ ). No significant effects were observed with $\mathrm{T}_{3}$. Neither $\mathrm{T}_{2}$ nor $\mathrm{T}_{3}$ affected mRNA expression of VLCAD in control cells (data not shown).

Stimulation of mitochondrial activity was confirmed by assessing expression of two other mitochondrial enzymes CPT1 and UCP2. In 'steatotic' cells, the expression of CPT1 and UCP2 was significantly up-regulated (about 1.8 and 1.6 fold with respect to control, 


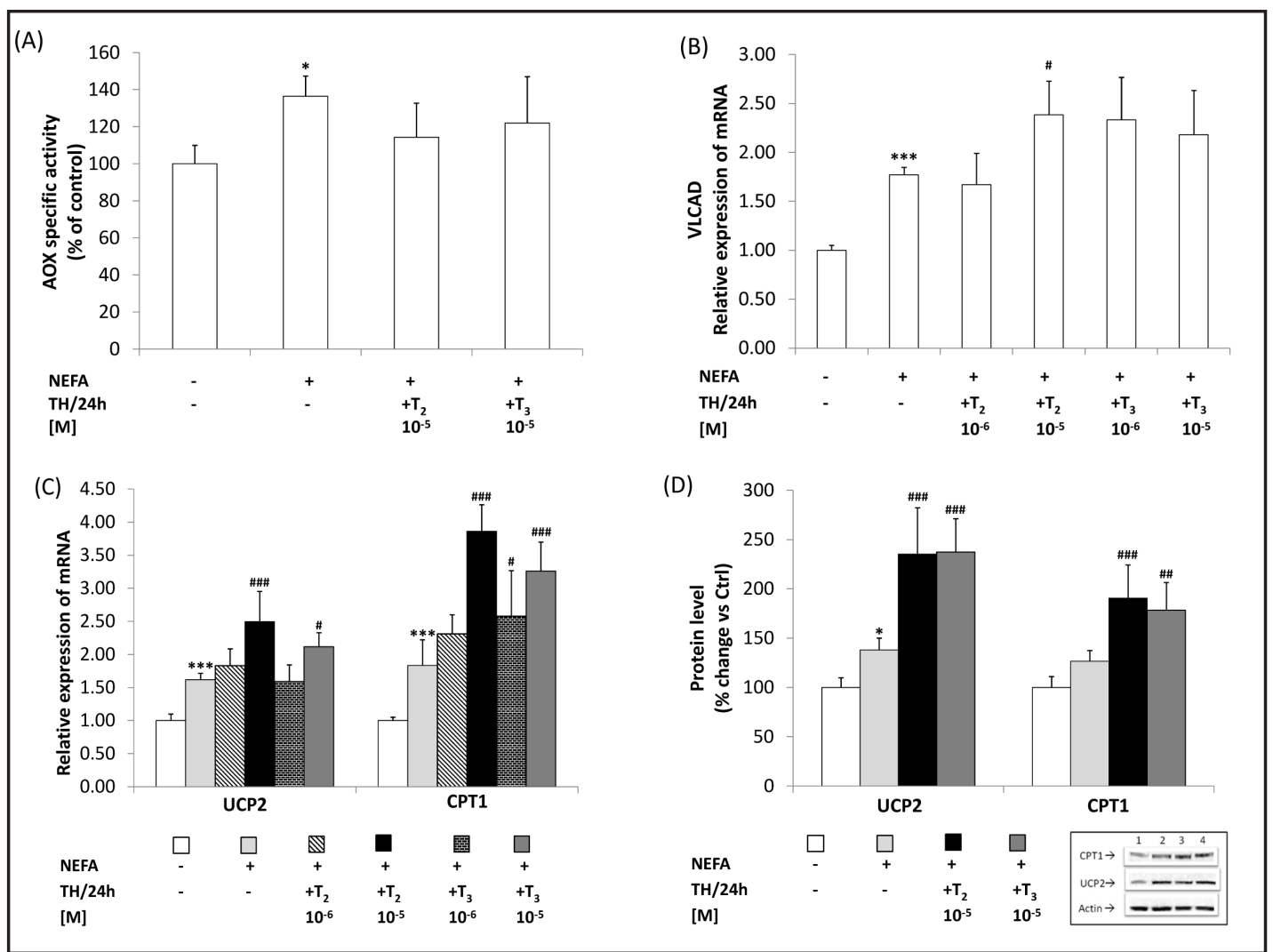

Fig. 5. $\mathrm{T}_{2}$ effects on peroxisomal and mitochondrial $\beta$-oxidation. (A) AOX specific activity (nmol $\mathrm{H}_{2} \mathrm{O}_{2} / \mathrm{min}$ per mg protein) was evaluated in control (C) and 'steatotic' cells incubated in the absence (NEFA) or in the presence of $\mathrm{T}_{2}$ or $\mathrm{T}_{3}\left(10^{-5} \mathrm{M}\right)$. Specific activity is expressed as percentage of controls and normalised for protein content. Data are the mean \pm S.D. of at least four experiments in triplicate. Significant differences are denoted by symbols on bars (C versus NEFA * $\mathrm{p} \leq 0.05$ ). (B) Relative mRNA expression of VLCAD was evaluated in control (C) and 'steatotic' cells incubated in the absence (NEFA) or in the presence of $\mathrm{T}_{2}$ or $\mathrm{T}_{3}\left(10^{-6}\right.$ and $\left.10^{-5} \mathrm{M}\right)$. Significant differences are denoted by symbols on bars (C versus NEFA *** $\mathrm{p} \leq 0.001$; NEFA versus THs \# p $\leq 0.05$ ). The mRNA (C) and protein levels (D) of CPT1, and UCP2 were evaluated by qPCR and western blot, respectively, in control (C) and 'steatotic' cells incubated in the absence (NEFA) or in the presence of $\mathrm{T}_{2}$ or $\mathrm{T}_{3}\left(10^{-5} \mathrm{M}\right)$. GAPDH was used as the internal control in qPCR, and actin was the protein loading control in SDS-PAGE (lane1: control, lane2: NEFA, lane3: NEFA+ $\mathrm{T}_{2} 10^{-5} \mathrm{M}$, lane4: $\mathrm{NEFA}+\mathrm{T}_{3}$ $10^{-5} \mathrm{M}$ ). Data are the mean \pm S.D. of at least four experiments in triplicate. Significant differences are denoted by symbols on bars (C versus NEFA ${ }^{* * *} \mathrm{p} \leq 0.001$; $^{*} \mathrm{p} \leq 0.05$; NEFA versus THs \#\#\# $\mathrm{p} \leq 0.001$; \#\# $\mathrm{p} \leq 0.01$; \# $\mathrm{p} \leq 0.05$ ).

respectively; $\mathrm{p} \leq 0.001$ ) (Fig. 5C). Treatment of 'steatotic' cells with $\mathrm{T}_{2}$ at the highest dose led to a further increase in mRNA expression of both genes (about $+110 \%$ for CPT1, and $+50 \%$ for UCP2 with respect to 'steatotic' cells; $\mathrm{p} \leq 0.001$ ). Similar effects were observed with $\mathrm{T}_{3}\left(10^{-5} \mathrm{M}\right)$ that increased the transcript levels of both CPT1 $(+78 \%, \mathrm{p} \leq 0.001)$, and UCP2 $(+31 \%, p \leq 0.05)$ with respect to 'steatotic' cells. General increases in UCP2 and CPT1 expression were observed in 'steatotic' cells with respect to controls, that were significant for UCP2 (about $+40 \%$; p $\leq 0.05$ ), but not for CPT1 (about+30\%) (Fig. 5D). Both CPT1 and UCP2 protein levels were further increased upon $\mathrm{T}_{2}$ treatment (about $+50 \%$ for CPT1, and $+70 \%$ for UCP2 with respect to 'steatotic' cells; $\mathrm{p} \leq 0.001$ ). Similar effects were observed with $\mathrm{T}_{3}$ that increased significantly the protein levels of both CPT1 (about $+40 \%$; $\mathrm{p} \leq 0.01$ ), and of UCP2 (about $+70 \%$; $\mathrm{p} \leq 0.001$ ) with respect to 'steatotic' cells. Neither $\mathrm{T}_{2}$ nor $\mathrm{T}_{3}$ affected mRNA and protein expression of CPT1 and UCP2 in control cells (data not shown). 
Grasselli et al.: $\mathrm{T}_{2}$ and Lipid Droplet Composition

\section{Discussion}

$\mathrm{T}_{2}$ is a naturally occurring iodothyronine that exerts some thyromimetic effects (for a review see [40]). $\mathrm{T}_{2}$ has been demonstrated able to reduce fat overload in the hepatocyte $[16,19-21,41]$, and this lipid-lowering action is not mediated by thyroid hormone receptors [21]. In the present study, we demonstrate that the lipid-lowering action of $\mathrm{T}_{2}$ is associated with modifications in the fatty acid composition of LDs in particular through a stimulation of the oxidative metabolism of saturated fatty acids (SFAs). It has to be noted that $\mathrm{T}_{2}$ was used at nominal doses higher than the physiological range; but, as previously discussed [20], these concentrations are often employed for in vitro experiments because of the more rapid metabolism rate of iodothyronines occurring in vitro with respect to in vivo [42], and because $\mathrm{T}_{2}$ is sequestered by BSA present at physiological concentrations in the medium [43]. On the other hand, a recent work by Mendoza et al. [44] showed that $\mathrm{T}_{2}$ was able to bind TR $\beta 1$ when used at lower doses $(100 \mathrm{nM})$, but that study employed cells transfected with different TR $\beta 1$ constructs.

To mimic in vitro the hepatic steatosis condition, FaO cells were exposed to an oleate/ palmitate mixture containing a higher concentration of $\mathrm{OA}$ to counteract the pro-apoptotic effects of PA [20, 21, 45]. In the hepatocyte, the exogenous NEFAs are esterified and stored into LDs. Several factors may induce mobilization of NEFAs from LDs through the hydrolysis of TAGs [46]. The released NEFAs have two predominant routes of disposal in the liver: oxidation in mitochondria and peroxisomes or export via VLDL [2], even though a large part of the released NEFAs is recycled back to LDs via a futile cycle [47].

Our results showed a decrease in the intracellular TAG content as well as a reduction in LD size after treatment of 'steatotic' cells with $\mathrm{T}_{2}$. This indicates that $\mathrm{T}_{2}$ might trigger a change from macrovesicular towards microvesicular steatosis, thus making the TAGs stored in LDs more accessible to lipolytic enzymes. The LD surface, in fact, is coated by the PAT proteins that manage access of lipases such as ATGL. ADRP, the most abundant PAT protein in hepatoma cells [48], promotes incorporation of lipids into LDs, while OXPAT regulates short-term utilization of lipids through oxidative pathways [3]. ATGL acts as a branch point in partitioning hydrolyzed NEFAs between oxidative and VLDL synthetic pathways, in particular by promoting NEFA delivery to mitochondrial oxidation rather than towards secretion [49]. Indeed, higher level of ATGL has been shown to stimulate lipolysis [50]. Both ADRP and OXPAT, as well as ATGL, were up-regulated in 'steatotic 'FaO cells, and, interestingly, $\mathrm{T}_{2}$ further increased their expression. Taken together our data suggest a pleiotropic action of $\mathrm{T}_{2}$ that, through ATGL and OXPAT up-regulation, may lead to mobilization of excess TAGs stored in LDs and direct the released NEFAs towards oxidative pathways.

The stimulation of lipid oxidation by $\mathrm{T}_{2}$ was confirmed by analysis of enzymes involved in mitochondrial $\beta$-oxidation. The mRNA expression of VLCAD was up-regulated by exposure to exogenous NEFAs, and it was further up-regulated by $\mathrm{T}_{2}$. On the other hand, also expression of CPT1 and UCP2, two enzymes regulating mitochondrial NEFA oxidation, was up-regulated in 'steatotic' cells and treatment with $\mathrm{T}_{2}$ allowed for a further increase in their expression at both mRNA and protein level. These data clearly indicate that $\mathrm{T}_{2}$ stimulates mitochondrial $\beta$-oxidation in 'steatotic' cells, and this effect well fits with previous results showing that $\mathrm{T}_{2}$ stimulates the fuel-induced $\mathrm{O}_{2}$ consumption in $\mathrm{FaO}$ cells, thus suggesting its uncoupling action on mitochondrial respiration [21,51]. Moreover, UCP2 seems to play a beneficial role in various stages of fatty liver diseases acting as anti-steatotic factor likely through a stimulation of mitochondrial respiration $[9,10]$. Therefore, induction of UCP2 along with that of CPT1 may be a part of a lipid detoxification effort of the hepatocyte [52]. By contrast, peroxisomal $\beta$-oxidation of fatty acids did not result stimulated by $\mathrm{T}_{2}$; in fact AOX activity was increased in 'steatotic ' $\mathrm{FaO}$ cells, but no significant changes could be appreciated upon $\mathrm{T}_{2}$ treatment. Taken together, these data suggest that $\mathrm{T}_{2}$ may exert its lipid-lowering effect mainly by enhancing NEFA mobilization from LDs and their oxidation at mitochondrial level.

In physiological conditions, hepatocytes deliver excess TAGs to peripheral tissues by production of VLDL. In 'steatotic' FaO cells, the level of TAGs in the extracellular medium 
was increased, thus indicating that lipid overload stimulates the cells to secrete TAGs in an attempt to reduce their excess. This is in accordance with a previous study showing that the content of secreted TAGs increased in an linear manner with time after incubation of cells with NEFAs [53]. Since the secretion of TAGs needs their packaging with ApoB to form the VLDL, we also assessed expression of this lipoprotein. In 'steatotic' cells we observed an upregulation of ApoB100 mRNA and protein expression, in accordance with previous studies on HepG2 cells [54]. When 'steatotic' cells were treated with $T_{2}$ the level of extracellular TAGs decreased as a consequence of the reduced lipid content. However, $\mathrm{T}_{2}$ per se did not affect the extracellular TAG levels (not shown). This suggest that the $\mathrm{T}_{2}$-induced reduction in the excess fat stored within LDs mainly occurs via stimulation of their hydrolysis and subsequent mitochondrial NEFA oxidation $[16,21]$, rather than of TAG secretion into the medium. Taken together our data indicate that $\mathrm{T}_{2}$ as well as $\mathrm{T}_{3}$ play similar effects on lipid metabolism and trafficking by acting mainly through TR-independent mechanisms [21] these could involve specific membrane-associated binding sites coupled with activation of rapid signaling pathways, such as those involving mitogen-activated protein kinases (MAPKs), phosphoinositol-3-kinase (PI3K), or $\mathrm{Ca}^{2+}$ mobilization [55]. However, the use of $\mathrm{T}_{3}$ as potential drug to treat obesity has collateral dangerous effects.

The lipid-lowering effect of $\mathrm{T}_{2}$ was confirmed by the gas chromatography analyses that showed a decrease in the total nmoles of esterified fatty acids purified from LDs upon $\mathrm{T}_{2}$ treatment. Moreover, $\mathrm{T}_{2}$ modified the acyl composition of LDs of 'steatotic' cells. Although we used a dose of oleate twice as high as that of palmitate, the LDs from 'steatotic' cells showed a lower incorporation of OA than PA, in line with previous reports [53]. Therefore, in 'steatotic' hepatocytes, OA is mainly oxidized, whereas PA is preferentially incorporated into TAGs and stored in LDs [56].On the other hand, in $\mathrm{T}_{2}$-treated cells, OA became the most abundant NEFA of LDs, whereas the PA content decreased, indicating that $\mathrm{T}_{2}$ would selectively stimulate PA oxidation. $\mathrm{T}_{2}$ also lead to a general decrease in the saturated fatty acid content of LDs, resulting in an inversion of the SFA/MUFA ratio. A higher lipotoxicity of SFAs than MUFAs was described in a variety of cells [57-59]. It is noteworthy that the endogenous biosynthesis of cholesterol preferentially starts from SFAs, and an inverse correlation was found between adipose tissue MUFAs and the cholesterol serum levels in healthy and diabetic subjects [60]. Moreover, a reduction in cholesterol serum level has been previously observed in HFD-fed rat treated with $\mathrm{T}_{2}$ [16]. Therefore, the effect of $\mathrm{T}_{2}$ in reducing the SFA content in LDs could contribute to the hypocholesterolemic effect of this iodothyronine.

In conclusion, our data indicate that $\mathrm{T}_{2}$ may stimulate oxidative metabolism of fatty acids, in particular of SFAs, and thus may enrich of MUFAs the TAGs stored in LDs. This action may protect the hepatic cell from an excessive accumulation of SFAs that have a higher toxicity with respect to unsaturated NEFAs. The lack for $\mathrm{T}_{2}$ of the thyrotoxic effects associated with long-term administration of $\mathrm{T}_{3}$ [61] makes $\mathrm{T}_{2}$ of great interest in the light of its possible utilization as a pharmacological tool in the treatment of dysmetabolic syndromes such as NAFLD and obesity.

\section{Acknowledgements}

We thank Drs. G. Vecchione, S. Ravera and S. Ferrando for their collaboration. A special thank to Prof. E. Fugassa for the constant support and encouragement.

Contract grant sponsor: MIUR-COFIN 2008; Fondazione CARIGE 2010; Compagnia San Paolo 2010.

\section{Conflict of Interest}

The authors declare that there is no conflict of interest that could be perceived as prejudicing the impartiality of the research reported. 


\section{Cellular Physiology Cell Physiol Biochem 2014;33:344-356

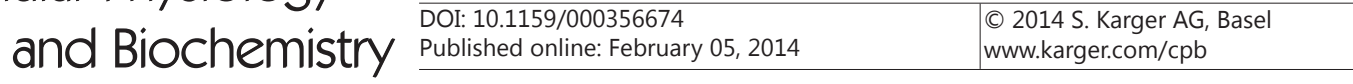 \\ Grasselli et al.: $\mathrm{T}_{2}$ and Lipid Droplet Composition}

\section{References}

1 Schaffer JE: Lipotoxicity: when tissues overeat. Curr Opin Lipidol 2003;14:281-287.

2 Murphy DJ: The biogenesis and functions of lipid bodies in animals, plants and microorganisms. Prog Lipid Res 2001;40:325-438.

3 Bickel PE, Tansey JT, Welte MA: PAT proteins, an ancient family of lipid droplet proteins that regulate cellular lipid stores. Biochim Biophys Acta 2009;1791:419-440.

-4 Rinia HA, Burger KNJ, Bonn M, Muller M: Quantitative Label-Free Imaging of Lipid Composition and Packing of Individual Cellular Lipid Droplets Using Multiplex CARS Microscopy. Biophys J 2008;95:49084914.

-5 Zimmermann R, Lass A, Haemmerle G, Zechner R: Fate of fat: The role of adipose triglyceride lipase in lipolysis. Biochim Biophys Acta 2009;1791:494-500.

-6 Haemmerle G, Lass A, Zimmermann R, Gorkiewicz G, Meyer C, Rozman J, Heldmaier G, Maier R, Theussl C, Eder S, Kratky D, Wagner EF, Klingenspor M, Hoefler G, Zechner R: Defective lipolysis and altered energy metabolism in mice lacking adipose triglyceride lipase. Science 2006;312:734-737.

7 Primassin S, Tucci S, Spiekerkoetter U: Hepatic and muscular effects of different dietary fat content in VLCAD deficient mice. Mol Genet Metab 2011;104:546-551.

8 Ramsay RR, Gandour RD, van der Leij FR: Molecular enzymology of carnitine transfer and transport. Biochim Biophys Acta 2001;1546:21-43.

-9 Baffy G: Uncoupling protein-2 and non-alcoholic fatty liver disease. Front Biosci 2005;10:2082-2096.

10 Demori I, Burlando B, Gerdoni E, Lanni A, Fugassa E, Voci A: Uncoupling protein-2 induction in rat hepatocytes after acute carbon tetrachloride liver injury. J Cell Physiol 2008;216:413-418.

11 Ricchi M, Odoardi MR, Carulli L, Anzivino C, Ballestri S, Pinetti A, Fantoni LI, Marra F, Bertolotti M, Banni S, Lonardo A, Carulli N, Loria P: Differential effect of oleic and palmitic acid on lipid accumulation and apoptosis in cultured hepatocytes. J Gastroenterol Hepatol 2009;24:830-840.

$\checkmark 12$ Higuchi K, Hospattankar AV, Law SW, Meglin N, Cortright J, Brewer HB: Human Apolipoprotein-B (Apob) Messenger-Rna - Identification of 2 Distinct Apob Messenger-Rnas, An Messenger-Rna with the Apob-100 Sequence and An Apob Messenger-Rna Containing A Premature In-Frame Translational Stop Codon, in Both Liver and Intestine. Proc Natl Acad Sci U S A 1988;85:1772-1776.

13 Ohsaki Y, Cheng JL, Suzuki M, Shinohara Y, Fujita A, Fujimoto T: Biogenesis of cytoplasmic lipid droplets: From the lipid ester globule in the membrane to the visible structure. Biochim Biophys Acta 2009;1791:399-407.

14 Gibbons GF, Islam K, Pease RJ: Mobilisation of triacylglycerol stores. Biochim Biophys Acta 2000;1483:3757.

15 Moreno M, Lombardi A, Beneduce L, Silvestri E, Pinna G, Goglia F, Lanni A: Are the effects of T-3 on resting metabolic rate in euthyroid rats entirely caused by T-3 itself? Endocrinology 2002;143:504-510.

16 Lanni A, Moreno M, Lombardi A, de Lange P, Silvestri E, Ragni M, Farina P, Baccari GC, Fallahi P, Antonelli A, Goglia F: 3,5-diiodo-L-thyronine powerfully reduces adiposity in rats by increasing the burning of fats. FASEB J 2005;19:1552-1554.

17 Antonelli A, Fallahi P, Ferrari SM, Di Domenicantonio A, Moreno M, Lanni A, Goglia F: 3,5-Diiodo-LThyronine Increases Resting Metabolic Rate and Reduces Body Weight Without Undesirable Side Effects. J Biol Regul Homeost Agents 2011;25:655-660.

18 Grasselli E, Canesi L, Voci A, De Matteis R, Demori I, Fugassa E, Vergani L: Effects of 3,5-diiodo-L-thyronine administration on the liver of high fat diet-fed rats. Exp Biol Med (Maywood) 2008;233:549-557.

19 Mollica MP, Lionetti L, Moreno M, Lombardi A, de Lange P, Antonelli A, Lanni A, Cavaliere G, Barletta A, Goglia F: 3,5-diiodo-l-thyronine, by modulating mitochondrial functions, reverses hepatic fat accumulation in rats fed a high-fat diet. J Hepatol 2009;51:363-370.

20 Grasselli E, Voci A, Canesi L, De Matteis R, Goglia F, Cioffi F, Fugassa E, Gallo G, Vergani L: Direct effects of iodothyronines on excess fat storage in rat hepatocytes. J Hepatol 2011;54:1230-1236.

21 Grasselli E, Voci A, Canesi L, Goglia F, Ravera S, Panfoli I, Gallo G, Vergani L: Non-receptor-mediated actions are responsible for the lipid-lowering effects of iodothyronines in $\mathrm{FaO}$ rat hepatoma cells. J Endocrinol 2011;210:59-69.

-22 Clayton DF, Weiss M, Darnell JE, Jr.: Liver-specific RNA metabolism in hepatoma cells: variations in transcription rates and mRNA levels. Mol Cell Biol 1985;5:2633-2641. 


\section{Cellular Physiology Cell Physiol Biochem 2014;33:344-356 and Biochemisty \begin{tabular}{l|l} 
DOI: 10.1159/000356674 2014 S. Karger AG, Basel & (C)
\end{tabular} \\ Grasselli et al.: $\mathrm{T}_{2}$ and Lipid Droplet Composition}

23 Lauris V, Crettaz M, Kahn CR: Coordinate roles of insulin and glucose on the growth of hepatoma cells in culture. Endocrinology 1986;118:2519-2524.

24 Grasselli E, Voci A, Pesce C, Canesi L, Fugassa E, Gallo G, Vergani L: PAT protein mRNA expression in primary rat hepatocytes: Effects of exposure to fatty acids. Int J Mol Med 2010;25:505-512.

-25 Ferrannini E, Barrett EJ, Bevilacqua S, Fronzo RA: Effect of fatty acids on glucose production and utilization in man. J Clin Invest 1983;72:1737-1747.

-26 Wiechelman KJ, Braun RD, Fitzpatrick JD: Investigation of the bicinchoninic acid protein assay: identification of the groups responsible for color formation. Anal Biochem 1988;175:231-237.

-27 Grandl M, Schmitz G: Fluorescent High-Content Imaging Allows the Discrimination and Quantitation of E-LDL-Induced Lipid Droplets and Ox-LDL-Generated Phospholipidosis in Human Macrophages. Cytometry Part A 2010;77A:231-242.

-28 Atshaves BP, Storey SM, McIntosh AL, Petrescu AD, Lyuksyutova OI, Greenberg AS, Schroeder F: Sterol carrier protein-2 expression modulates protein and lipid composition of lipid droplets. J Biol Chem 2001;276:25324-25335.

29 Folch J, Less M, Sloane Stanely GH: A simple method for the isolation and purification of total lipides from animal tissues. J Biol Chem 1957;226:497-509.

-30 Morrison WR, Smith LM: Preparation of fatty acid methyl esters and dimethylacetals from lipids with boron fluoride. J Lipid Res 1964;5:600-608.

-31 Chomczynski P, Sacchi N: Single-step method of RNA isolation by acid guanidinium thiocyanate-phenolchloroform extraction. Anal Biochem 1987;162:156-159.

32 Distel E, Penot G, Cadoudal T, Balguy I, Durant S, Benelli C: Early induction of a brown-like phenotype by rosiglitazone in the epicardial adipose tissue of fatty Zucker rats. Biochimie 2012;94:1660-1667.

-33 Romero MM, Vila R, Fernandez-Lopez JA, Esteve M, Alemany M: Influence of oleoyl-estrone treatment on circulating testosterone. Role of 17 beta-hydroxysteroid dehydrogenase isoenzymes. J Physiol Pharmacol 2009;60:181-190.

-34 Spann NJ, Kang S, Li AC, Chen AZ, Newberry EP, Davidson NO, Hui ST, Davis RA: Coordinate transcriptional repression of liver fatty acid-binding protein and microsomal triglyceride transfer protein blocks hepatic very low density lipoprotein secretion without hepatosteatosis. J Biol Chem 2006;281:33066-33077.

35 Pfaffl MW: A new mathematical model for relative quantification in real-time RT-PCR. Nucleic Acids Res 2001;29: e45.

-36 Laemmli UK: Cleavage of structural proteins during the assembly of the head of bacteriophage T4. Nature 1970;227:680-685.

37 Towbin H, Staehelin T, Gordon J: Electrophoretic transfer of proteins from polyacrylamide gels to nitrocellulose sheets: Procedure and some applications. Proc Natl Acad Sci U S A 1979;72:4350-4354.

-38 Small GM, Burdett K, Connock MJ: A sensitive spectrophotometric assay for peroxisomal acyl-CoA oxidase. Biochem J 1985;227:205-210.

39 Smirnova E, Goldberg EB, Makarova KS, Lin L, Brown WJ, Jackson CL: ATGL has a key role in lipid droplet/ adiposome degradation in mammalian cells. Embo Rep 2006;7:106-113.

-40 Cioffi F, Senese R, Lanni A, Goglia F: Thyroid hormones and mitochondria: With a brief look at derivatives and analogues. Mol Cell Endocrinol 2013;doi:pii: S0303-7207(13)00244-X.

41 Grasselli E, Voci A, Demori I, Canesi L, De Matteis R, Goglia F, Lanni A, Gallo G, Vergani L: 3,5-Diiodo-Lthyronine modulates the expression of genes of lipid metabolism in a rat model of fatty liver. J Endocrinol 2012;212:149-158.

42 Mariash CN, Oppenheimer JH: Interrelationship of triiodothyronine concentration, metabolism, protein binding, and nuclear occupancy in the induction of malic enzyme by cultured adult rat hepatocytes. Endocrinology 1983;112:80-85.

43 Wilson EJ, McMurray WC: Regulation of malic enzyme and mitochondrial alphaglycerophosphate dehydrogenase by thyroid hormones, insulin, and glucocorticoids in cultured hepatocytes. J Biol Chem 1981;256:11657-11662.

44 Mendoza A, Navarrete-Ramirez P, Hernandez-Puga G, Villalobos P, Holzer G, Renaud JP, Laudet V, Orozco A: 3,5-T-2 Is an Alternative Ligand for the Thyroid Hormone Receptor beta 1. Endocrinology 2013;154:29482958.

45 Listenberger LL, Han XL, Lewis SE, Cases S, Farese RV, Ory DS, Schaffer JE: Triglyceride accumulation protects against fatty acid-induced lipotoxicity. Proc Natl Acad Sci U S A 2003;100:3077-3082. 


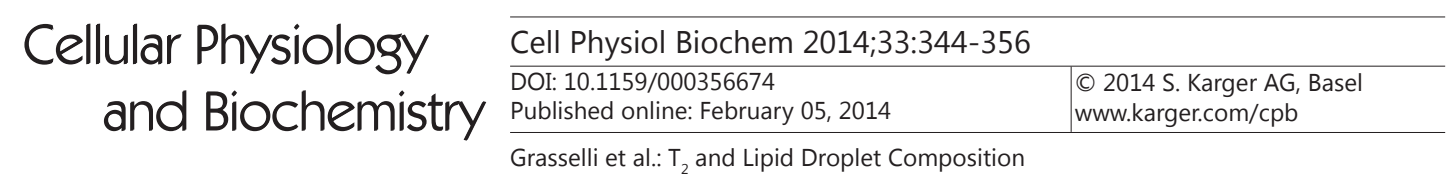

46 Wang HJ, Wei EH, Quiroga AD, Sun XJ, Touret N, Lehner R: Altered Lipid Droplet Dynamics in Hepatocytes Lacking Triacylglycerol Hydrolase Expression. Mol Biol Cell 2010;21:1991-2000.

47 Wiggins D, Hems R, Gibbons GF: Decreased Sensitivity to the Inhibitory Effect of Insulin on the Secretion of Very-Low-Density Lipoprotein in Cultured-Hepatocytes from Fructose-Fed Rats. Metabolism 1995;44:841847.

48 Fujimoto Y, Itabe H, Sakai J, Makita M, Noda J, Mori M, Higashi Y, Kojima S, Takano T: Identification of major proteins in the lipid droplet-enriched fraction isolated from the human hepatocyte cell line HuH7. Biochim Biophys Acta. 2004;1644:47-59.

49 Reid BN, Ables GP, Otlivanchik OA, Schoiswohl G, Zechner R, Blaner WS, Goldberg IJ, Schwabe RF, Chua SC Jr, Huang LS: Hepatic overexpression of hormone-sensitive lipase and adipose triglyceride lipase promotes fatty acid oxidation, stimulates direct release of free fatty acids, and ameliorates steatosis. J Biol Chem 2008;283:13087-13099.

-50 Bell M, Wang H, Chen H, McLenithan JC, Gong DW, Yang RZ, Yu DZ, Fried SK, Quon MJ, Londos C, Sztalryd C: Consequences of lipid droplet coat protein downregulation in liver cells: abnormal lipid droplet metabolism and induction of insulin resistance. Diabetes 2008;57:2037-2045.

-51 Cavallo A, Priore P, Gnoni GV, Papa S, Zanotti F, Gnoni A: 3,5-Diiodo-L-Thyronine Administration To Hypothyroid Rats Rapidly Enhances Fatty Acid Oxidation Rate and Bioenergetic Parameters in Liver Cells. Plos One 2013;8: e52328.

52 Wang MY, Shimabukuro M, Lee Y, Trinh KY, Chen JL, Newgard CB, Unger RH: Adenovirus-mediated overexpression of uncoupling protein-2 in pancreatic islets of Zucker diabetic rats increases oxidative activity and improves beta-cell function. Diabetes 1999;48:1020-1025.

-53 Bruce JS, Salter AM: Metabolic fate of oleic acid, palmitic acid and stearic acid in cultured hamster hepatocytes. Biochem J 1996;316:847-852.

54 Moberly JB, Cole TG, Alpers DH, Schonfeld G: Oleic-Acid Stimulation of Apolipoprotein-B Secretion from Hepg2 and Caco-2 Cells Occurs Posttranscriptionally. Biochim Biophys Acta1990;1042:70-80.

55 Bergh JJ, Lin HY, Lansing L, Mohamed SN, Davis FB, Mousa S, Davis PJ: Integrin alpha(v)beta(3) contains a cell surface receptor site for thyroid hormone that is linked to activation of mitogen-activated protein kinase and induction of angiogenesis. Endocrinology 2005;146:2864-2871.

-56 Gaster M, Rustan AC, Beck-Nielsen H: Differential utilization of saturated palmitate and unsaturated oleate - Evidence from cultured myotubes. Diabetes 2005;54:648-656.

-57 Cnop M, Hannaert JC, Hoorens A, Eizirik DL, Pipeleers DG: Inverse relationship between cytotoxicity of free fatty acids in pancreatic islet cells and cellular triglyceride accumulation. Diabetes 2001;50:1771-1777.

-58 Hardy S, Langelier Y, Prentki M: Oleate activates phosphatidylinositol 3-kinase and promotes proliferation and reduces apoptosis of MDA-MB-231 breast cancer cells, whereas palmitate has opposite effects. Cancer Res 2000;60:6353-6358.

-59 Listenberger LL, Ory DS, Schaffer JE: Palmitate-induced apoptosis can occur through a ceramideindependent pathway. J Biol Chem 2001;276:14890-14895.

60 Korani M, Firoozrai M, Maleki J, Ghahramanpour F, Heidari I, Fallah S, Seifi M: Distribution of Fatty Acids in Adipose Tissue of Patients with Type 2 Diabetes. Clin Lab 2012;58:457-464.

61 Cimmino M, Mion F, Goglia F, Minaire Y, Geloen A: Demonstration of in vivo metabolic effects of 3,5-diiodothyronine. J Endocrinol 1996;149:319-325. 